\title{
ROS and Ions in Cell Signaling during Sexual Plant Reproduction
}

\author{
Maria Breygina * ${ }^{*}$ and Ekaterina Klimenko \\ Department of Plant Physiology, Biological Faculty, Lomonosov Moscow State University, \\ 119991 Moscow, Russia; kleo80@yandex.ru \\ * Correspondence: breygina@mail.bio.msu.ru; Tel.: +7-499-939-1209
}

Received: 25 November 2020; Accepted: 10 December 2020; Published: 13 December 2020

check for updates

\begin{abstract}
Pollen grain is a unique haploid organism characterized by two key physiological processes: activation of metabolism upon exiting dormancy and polar tube growth. In gymnosperms and flowering plants, these processes occur in different time frames and exhibit important features; identification of similarities and differences is still in the active phase. In angiosperms, the growth of male gametophyte is directed and controlled by its microenvironment, while in gymnosperms it is relatively autonomous. Recent reviews have detailed aspects of interaction between angiosperm female tissues and pollen such as interactions between peptides and their receptors; however, accumulated evidence suggests low-molecular communication, in particular, through ion exchange and ROS production, equally important for polar growth as well as for pollen germination. Recently, it became clear that ROS and ionic currents form a single regulatory module, since ROS production and the activity of ion transport systems are closely interrelated and form a feedback loop.
\end{abstract}

Keywords: pollen germination; pollen tube growth; ROS; ions; plant reproduction

\section{Introduction}

Reactive oxygen species (ROS) in plant tissues are a universal regulatory element associated with various signaling systems, such as phospholipids, calcium, and ROP (Rho of plants) GTPases. The participation of ROS in intercellular cross-talk and morphogenesis at the cellular level, for example, during stomatal movements, zygote polarization, and root hair growth, has been convincingly shown [1-4].

Sexual reproduction in plants has been extensively studied since this area has both fundamental and practical significance. Most of the data on male gametophyte germination was obtained in vitro, since pollen cultivation is an accessible and convenient technique that allows one to simplify the experimental system. However, recently, many studies have focused on the interaction (1) between gametophytes and (2) of male gametophyte with female tissues of sporophyte [5-7]. In this case, regulatory factors found in vitro are tested for in vivo efficacy, mainly using genetic approach and improved fluorescence techniques. A lot of attention is paid to the interactions of peptides with their receptors which provide the control of pollen tube growth by female tissues [8]. However, the accumulated evidence suggests also low-molecular communication between sporophyte tissues and pollen, in particular, through ion exchange and production of ROS [6,7]. The ability of pollen grains to respond to changes in ionic environment was discovered around 45 years ago [9], and recently, it became clear that ROS and ionic currents form a single regulatory system, since ROS production and the activity of ion transporters are tightly interrelated [10,11]. 


\section{Pollen Germination}

\subsection{ROS Production as an Early Event during Germination}

When a dry, dormant pollen grain lands on a stigma or on the scales of a female cone, it rehydrates and gradually switches to active metabolism [12]. One of the first physiological changes, apparently, is ROS production, since NBT staining reveals ROS in the aperture area already after 5 minutes of in vitro pollen incubation in kiwi [13]; staining of non-germinated tobacco pollen grains with ROS-sensitive dyes displays their apoplastic and mitochondrial localization [14]. ROS production has also been described in non-germinated pollen grains of Arizona cypress [15]. Mitochondrial ROS production must be tightly controlled, as its excess, for example, in defective pollen leads to cell death and, as a consequence, to cytoplasmic male sterility (CMS) [16]. The involvement of ROS in pollen abortion has been reported for many cytoplasm male sterile crop varieties, for example, cotton [17], pepper [18], and rice [19]. In these cases, excessive ROS production was associated with reduced abundance of superoxide dismutase (SOD), ascorbate peroxidase (APX), catalase [19], and peroxisomal-like protein [17] in mitochondria.

Besides their generation in mitochondria, ROS in pollen are produced on the plasma membrane of vegetative cell and can be accumulated in the apoplast. ROS release from pollen grains in vitro was recorded after 20 minutes in tobacco and kiwi [13,14] and after $10 \mathrm{~min}$ in spruce [20]. In these cases, ROS production was associated with NADPH oxidase, since its inhibitor DPI (diphenyl iodonium) suppressed ROS accumulation in the germination medium [14,20] and ROS synthesis in pollen grains [13,15]. In Arabidopsis pollen, two isoforms of plasma membrane NADPH oxidase are involved in ROS synthesis: RbohH and RbohJ (respiratory burst oxidase protein homolog) [21]. Cytochemical analysis of pollen grains germinating on stigma showed that double mutants $r b o h H$, lack $\mathrm{H}_{2} \mathrm{O}_{2}$ accumulation in the apoplast, which is typical for wild-type pollen [22]. SOD and MnTMPP (ROS quencher that mimics the activity of SOD and catalase) severely reduce pollen germination efficiency in blue spruce [20]. A negative effect has been also reported for cypress [15]. In angiosperms, the situation is, apparently, more complicated than in conifers since the balance of ROS production/elimination largely depends on pistil tissues. Thus, in tobacco, low concentrations of ascorbic acid and DPI reduce ROS content in pollen, but stimulated germination as well as MnTMPP [23]. This data indicates that the level of ROS produced by tobacco pollen is excessive relative to optimal. However, no such effect was observed in kiwi; all investigated concentrations of antioxidants blocked pollen germination [13]. Taken together, the facts described indicate the importance of endogenous ROS and, in particular, NADPH oxidase-derived ROS during initial germination stages in both angiosperms and conifers.

During in vivo germination in Arabidopsis, ROS synthesis is very important already at the stage of pollen grain hydration [24]. Snf1(sucrose nonfermenting 1)-related kinase1 protein kinase complex belongs to a family of highly conserved serine/threonine kinases and is involved in pollen, embryo, seedling and organ development regulation as well as in sugar, stress and hormonal signaling. It turned out that the mutant lacking subunit KIN $\beta \gamma$ of SnRK1 protein complex simultaneously exhibit a reduced level of endogenous ROS and hydration disorders, which did not appear in vitro (when water was in excess), as well as when water was added on the stigma. The same disturbances were observed upon overexpression of catalase, which drastically reduced the level of endogenous $\mathrm{H}_{2} \mathrm{O}_{2}$ in pollen [24]. Thus, a relationship was revealed between ROS production at the early germination stage and water flow into dry pollen grains.

\subsection{Changes of Ionic Status during Early Germination Stages}

In parallel with ROS production, the exact time of which has not been established, since it may differ for different species, active protein synthesis begins, and pollen starts the preparation for polar growth, which includes significant changes in ionic homeostasis. One of the earliest events is the release of anions from pollen grains [25]; in tobacco it begins within 2 minutes of incubation. Other early changes include cytoplasmic $\mathrm{pH}$ shift towards alkaline values and hyperpolarization 
of the plasmalemma [26,27], in tobacco they occur simultaneously. Experiments with proton pump inhibitor and activator demonstrate significance of this enzyme in triggering the early germination stages, apparently due to the cytoplasm alkalization [27-30]. The $\mathrm{H}^{+}$-ATPase can also take part in plasma membrane hyperpolarization, together with anion channels: suppression of their activity blocks membrane potential (MP) shift in tobacco pollen [25].

When metabolism activation is completed, pollen grain undergoes polarization and segregation of the germination pole (cytoplasmic zone where a pollen tube will form). This domain differs from other zones in the arrangement of organelles: clusters of vesicles and mitochondria, which will provide the delivery of membrane material and energy for pollen tube growth, are accumulated at the germination pole [31]. However, some time before the polar growth is launched and cytoplasm protrusion becomes noticeable, physiological segregation of the pole occurs, for which ionic currents are essential. In early studies, electric currents crossing lily pollen grain were recorded, which, apparently, set the polarity for future germination [9,32]. On Arabidopsis pollen, it was shown that 9-15 minutes after in vivo pollination, a local increase in the intracellular calcium concentration begins in the germination pole [33]; it apparently causes NADPH oxidase activation and subsequent local ROS synthesis [21].

\subsection{ROS Production on Stigma}

ROS synthesis and ion currents at the early germination stage are interrelated and can stimulate each other forming a regulatory feedback loop; however, this system may involve not only endogenous ROS (synthesized by pollen) but also exogenous ROS coming from the sporophyte tissues. A current hypothesis states that ROS synthesis should be considered, inter alia, as a way of activating and/or supporting pollen germination by female tissues.

ROS are synthesized on stigmas of various (if not all) flowering plants; in total, more than 20 species from different families have been studied to date, and this property is common for all studied species [5,34-36]. According to inhibitory experiments, the main ROS on stigma is hydrogen peroxide $[35,36]$. The presence of various ROS-regulating enzymes, in particular, peroxidases $[37,38]$, on stigma and in stigma exudate has been widely accepted. On the other hand, in vitro pollen grain diffusates caused the inhibition of peroxidase activity [39]. Thus, the final balance between ROS production and elimination during in vivo germination in flowering plants is the result of a complex interaction between sporophyte and male gametophyte, which includes both low molecular weight components and antioxidant enzymes.

\subsection{Perception of Exogenous ROS Signal by Pollen}

Moderate $\mathrm{H}_{2} \mathrm{O}_{2}$ concentrations activate pollen germination in tobacco, while high concentrations inhibit [23]; for kiwi, high peroxide concentrations also have an inhibitory effect [13]. In spruce, the latter effect did not appear - the presence of ROS in a wide concentration range $(0.1-2 \mathrm{mM})$ does not reduce the germination efficiency [20]; So far, it can be assumed that during pollen germination in gymnosperms, female tissues (cones) do not produce noticeable amounts of superoxide radical or peroxide, and only endogenous ROS are used to activate ion currents and other physiological effects in pollen. To confirm or disprove this hypothesis, one needs to find out if there are ROS in female cones before and during pollination.

One of the functions performed by ROS in plant cell is the control of cell wall cytomechanics. Moreover, while some ROS loosen the extracellular matrix, others, on the contrary, promote cross-linking of polymers [40]. Wall loosening can occur by non-protein-mediated scission of polysaccharides through $\bullet \mathrm{OH}$ attack [41], while $\mathrm{H}_{2} \mathrm{O}_{2}$ can strengthen polymers via peroxidase-mediated cross-linking of hydroxycinnamates [42]. As shown in tobacco, this function is critical for pollen grains: a shift in ROS balance leads to impaired pollen germination. Hence, pollen grains treated with an excess of - $\mathrm{OH}$ were unstable to hypotonic stress and burst, and those treated with high concentrations of $\mathrm{H}_{2} \mathrm{O}_{2}$ became too hard and could not launch polar growth although remained viable [23]. For gymnosperms, ROS-mediated regulation of cell wall stiffness determines not only the germination efficiency, but also 
the pattern of pollen tubes appearance: in many species of the Pinaceae family, two tubes can appear from one pollen grain $[43,44]$, which, as it turned out, depends not on the availability of nutrients, but mainly on the properties of the pollen wall regulated by ROS [43].

However, ROS functions are not limited to the cell wall. Exogenous ROS, affecting pollen in flowering plants, can specifically activate ion channels: in protoplasts from lily pollen grains, calcium and potassium currents are stimulated by $\mathrm{H}_{2} \mathrm{O}_{2}(100 \mu \mathrm{M})$ [45]; in pear pollen protoplasts $10 \mathrm{mM} \mathrm{H}_{2} \mathrm{O}_{2}$ activates the calcium current [46]. For tobacco, similar results were obtained in different concentration range: intracellular $\left[\mathrm{Ca}^{2+}\right]$ was assessed by a fluorescent method, and it clearly reacted to peroxide already at $10 \mu \mathrm{M}$. The effect was abolished by calcium channel inhibitor nifedipine [47]. Another important effect was the plasma membrane hyperpolarization in $\mathrm{H}_{2} \mathrm{O}_{2}$-treated protoplasts $(10 \mu \mathrm{M})[47]$.

Thus, for angiosperms (although we can speak with confidence only of a few species), ROS, and in particular $\mathrm{H}_{2} \mathrm{O}_{2}$, are an important product of female sporophyte tissues enhancing germination, causing membrane hyperpolarization, activation of calcium currents, and, possibly, other more delayed effects.

\section{Pollen Tube Growth}

The pollen tube of angiosperms is characterized by an extremely rapid growth, which is supported by physiological and structural zoning of the cytoplasm [48]. It is generally accepted to distinguish apical, subapical, and distal domains in the pollen tube; the distal, in turn, has its own subdivisions, based on the presence of certain organelles in it. The segregation of cytoplasmic zones is maintained due to a set of regulatory mechanisms, including small GTPases and signaling phospholipids, which are highlighted in a recent review [49]; here, we focus on those that have become the subject of the present review.

Endogenous mechanisms maintaining the polar growth are conveniently studied in vitro, but female sporophyte tissues produce a number of their own molecules that can influence tube growth by enhancing, directing, or blocking it. In particular, the direction of tube growth can be affected by $\left[\mathrm{Ca}^{2+}\right], \mathrm{NO}$, and ROS in pistil tissues, and the latter can both support growth and stop it if fertilization is undesirable $[7,50,51]$.

\subsection{Ionic Homeostasis and ROS Production in Growing Pollen Tube}

The uneven distribution and activity of ion transporters cells with polar growth results in gradients of ion concentrations and membrane potential (MP) corresponding to different cell domains (Figure 1). Thus, $\left[\mathrm{Ca}^{2+}\right]$ is highest in the apical domain [52]; $\mathrm{pH}-$ in subapical; concentration of anions-20 to $50 \mu \mathrm{m}$ from the tip (Arabidopsis thaliana) [53]. MP has the lowest (relatively depolarized) value at the tip; further along the tube length, hyperpolarization is observed $[20,54,55]$. At the moment, the gradient has already been described in pollen tubes of both flowering plants (tobacco, lily) and conifers (spruce). According to inhibitory analysis, at least $\mathrm{H}^{+}$-ATPase and anion channels take part in its maintenance, and for spruce potassium and calcium channels are also involved. Some of these systems are sensitive to endogenous and exogenous ROS, since the gradient changes shape in the presence of both $\mathrm{H}_{2} \mathrm{O}_{2}$, antioxidants, and DPI $[20,55]$. Interestingly, the sensitivity of pollen tubes to hydrogen peroxide is higher in spruce than that in lily: in spruce, depolarization in subapical region was observed already at $100 \mu \mathrm{M} \mathrm{H}_{2} \mathrm{O}_{2}$, while in lily the effect was observed at $500 \mu \mathrm{M}$, and it was hyperpolarizing. A decrease in the endogenous ROS level in both cases led to hyperpolarization and dissipation of the gradient. Considering these data together with the results obtained on protoplasts from tobacco pollen tubes [47], we can conclude that MP is an indicator with high sensitivity to $\mathrm{H}_{2} \mathrm{O}_{2}$, which means that systems responsible for maintaining the MP gradient can respond to both endogenous ROS, at least partially generated by NADPH oxidase, and ROS produced by female sporophyte tissues. 


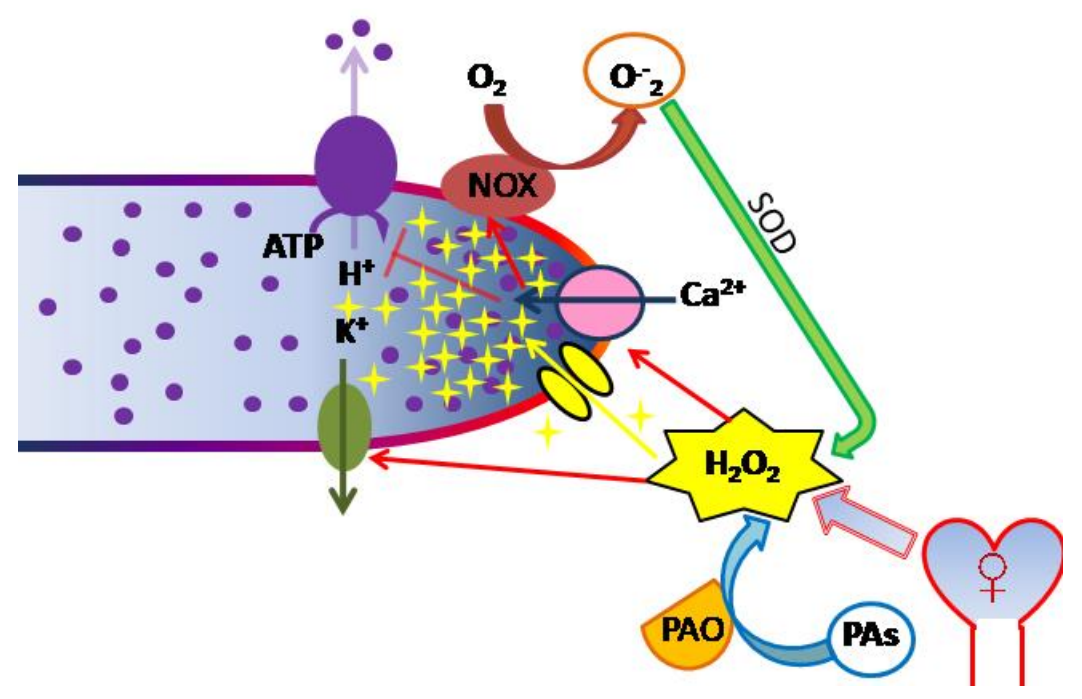

Figure 1. ROS and ion homeostasis in the regulation of pollen tube growth (simplified diagram). Three sources of apoplastic ROS during pollen tube growth are shown: NOX in the plasma membrane produces superoxide radical, SOD dismutates it to hydrogen peroxide; PAO produces $\mathrm{H}_{2} \mathrm{O}_{2}$ during polyamine oxidation; female tissues of the sporophyte produce ROS that control pollen tube growth in vivo. Hydrogen peroxide enters the pollen tube through aquaporins and forms apical ROS accumulation (yellow stars). The main targets for apoplastic ROS are shown: $\mathrm{Ca}_{2+}$ permeable ion channels and $\mathrm{K}^{+}$-permeable ion channels are activated by $\mathrm{H}_{2} \mathrm{O}_{2}$, lateral membrane potential is affected (apex is red (depolarized), shank is blue (hyperpolarized)). Apical calcium gradient in the cytoplasm is shown in blue color. High $\left[\mathrm{Ca}^{2+}\right]$ reduces the proton pump activity, which forms the alkaline band (protons shown as circles). NOX-NADPH-oxidase, SOD-superoxidedismutase, PAO_polyamineoxidase, Pas-polyamines.

In growing pollen tubes, $\mathrm{pH}$ gradient is maintained: $\mathrm{pH}$ at the tip is acidic, in the subapical zone it rises to alkaline values due to $\mathrm{H}^{+}$-ATPase activity, and along the tube shank, $\mathrm{pH}$ is close to neutral [55-57] (Figure 1). $\mathrm{pH}$ gradient is affected by significant alterations in ROS production/elimination balance: in MnTMPP-treated in lily pollen tubes $\mathrm{pH}$ shifts towards more alkaline values, wherein the difference between apical and subapical zones is leveled [55]; during short-term exposure to $1 \mathrm{mM} \mathrm{H}_{2} \mathrm{O}_{2}$ the alkaline band disappears, the gradient is also leveled; lower concentrations do not affect $\mathrm{pH}$ [55]. The authors suggest that the observed effect in $\mathrm{H}_{2} \mathrm{O}_{2}$-treated tubes can be explained by the suppression of $\mathrm{H}^{+}$-ATPase activity by high $\left[\mathrm{Ca}^{2+}\right.$ ], since peroxide stimulates calcium channels [45] (Figure 1). Thus, ROS directly or indirectly regulate the proton pump activity in lily pollen tubes and maintain gradient $\mathrm{pH}$ distribution in the cytoplasm.

In all studied pollen tubes, there is a gradient of intracellular calcium concentration: in flowering plants, apical $\left[\mathrm{Ca}^{2+}\right]$ is two orders of magnitude higher than that in the shank [52,58]; gymnosperms have a flatter gradient [59]. ROS production is important for maintaining normal calcium homeostasis: in lily tubes, MnTMPP, even at low concentrations, caused a decrease in calcium concentration and dissipation of $\left[\mathrm{Ca}^{2+}\right]$ gradient [55].

Downstream of $\left[\mathrm{Ca}^{2+}\right]$ and $\mathrm{pH}$ is the structure and dynamics of actin cytoskeleton controlled by numerous proteins [60]. Among $\mathrm{Ca}^{2+}$-dependent actin-binding proteins, for example, profilin, LIM domain-containing proteins, ROP-interactive and CRIB motif-containing protein1 (RIC1), and villins should be mentioned [61]. High $\left[\mathrm{Ca}^{2+}\right]$ in the tube tip supports actin remodeling and ensures its existence in the form of sparse short filaments while low $\left[\mathrm{Ca}^{2+}\right]$ in the shank area correlates with rather thick and stable actin cables; the main mediators in this relationship are proteins from villin/gelsolin/fragmin superfamily [60,61]; subapical actin fringe is tightly associated with the alkaline band, presumably, via actin depolimerizing factor (ADF) and actin-interacting protein 1 (AIP1) [62,63]. 
Thus, by provoking $\mathrm{Ca}^{2+}$ influx in the pollen tube tip and regulating intracellular $\mathrm{pH}, \mathrm{ROS}$ can thereby affect the actin cytoskeleton.

Since, as has been revealed in protoplasts, calcium transport is closely related to ROS production, one might assume that ROS are also unevenly distributed in the pollen tube. This has been shown by different methods for Arabidopsis [64,65], Pyrus [66], cypress [15], and two Picea species [20,67]. For spruce, it was shown that $\mathrm{H}_{2} \mathrm{O}_{2}$ accumulates in the tube apex, apparently coming from the apoplast (where NADPH oxidase and SOD work) (Figure 1), and in amyloplasts, while most of the $\mathrm{O}_{2}{ }_{2}^{-}$is produced in mitochondria, and the localization of the two ROS does not coincide [20].

ROS are produced in pollen tubes by RbohH and RbohJ. Both proteins located on the pollen tube plasma membrane have EF-hands in their structure and are activated upon binding of calcium ion [21]. In tobacco, transfection with NOX-specific antisense oligodeoxynucleotides (ODNs) resulted in pollen tube growth inhibition, which was rescued by exogenous $\mathrm{H}_{2} \mathrm{O}_{2}$ [68]. In Arabidopsis, rbohH,J mutants have severe reproductive disorders. The mutant's pollen has inhibited tube growth and impaired calcium homeostasis [21,69]. Interestingly, mutants for calcium channel genes $c n g c 7,8$ (cyclic nucleotide gated, non-selective, $\mathrm{Ca}_{2+}$-permeable ion channels) have phenotypes almost identical to rbohH,J, which indicates the feedback regulation of these systems [7]. The features of the rbohH,J mutants were revealed in vivo: in wild-type Arabidopsis plants, apoplastic ROS production in the area between the pollen tube surface and stigma papilla was detected by histochemistry [22]. In mutants, ROS did not accumulate; growth was impaired. Thus, endogenous ROS produced by NADPH oxidase are essential for pollen tube growth in vitro and in vivo.

However, this enzyme is not the only source of ROS in the male gametophyte: polyamine oxidase (PAO) in pollen can synthesize $\mathrm{H}_{2} \mathrm{O}_{2}$ from polyamines [70] (Figure 1). In Oryza sativa seven PAO isoforms have been identified, and one of these, OsPAO7, is specifically expressed in anthers; OsPAO7 produces $\mathrm{H}_{2} \mathrm{O}_{2}$ about 100 times more efficiently than other PAO isoforms [71]. In a recent study the relationship between polyamines and $\mathrm{H}_{2} \mathrm{O}_{2}$ in Arabidopsis pollen tubes was reported [65]. Such a relationship had been previously shown for pear: the gradients of total ROS and spermidine in these tubes coincided, and in spermidine-treated tubes $(100 \mu \mathrm{M})$ cytoplasmic level of these substances increased consistently [66]. It is to be noted that the same exogenously applied polyamines had different effects on the NO/ROS levels pollen grains and tubes. Furthermore, recent studies indicate that PAs regulate pollen germination primarily via regulating the ROS level, while tube elongation primarily influencing the NO level [72].

Polyamines can affect ion homeostasis in plant cells, in many cases, in an indirect manner, with ROS formation as an intermediate stage [70,72,73]. For example, upon treatment with $100 \mu \mathrm{M}$ spermidine, pear pollen tubes responded with a rapid $\left[\mathrm{Ca}^{2+}\right]_{\mathrm{cyt}}$ increase, $\mathrm{pH}$ gradient alterations, and switch of growth pattern [74]. The data on polyamine-induced changes in ion transport in root cells is much more plentiful: $\mathrm{H}^{+}$-ATPase pumping activity was affected in several species, including both activation (in rice and wheat) and inhibition (in maize) [73]. In some cases, polyamines can cause pollen damage through excessive ROS formation, followed by activation of the antioxidant machinery, degradation of nuclear DNA, and finally, cell death [66].

An $\mathrm{ABC}$ transporter carrying polyamines is involved in forming the ROS gradient early during polar growth: short tubes of atabcg28 (ATP-binding cassette G28) mutant lack the gradient of both total ROS and hydrogen peroxide with maximum at the tip, typical for wild type tubes [65]. It should be noted, however, that total ROS level in this pollen is high, and normal tubes are not formed.

According to colocalization experiments with both fluorescence microscopy and TEM, mitochondria in the pollen tube are also a source of ROS [20,75,76]; however, the role of mitochondriaderived ROS in the regulation of polar growth is still questionable. To date, their reduced production has been associated with loss of mitochondrial function in self-incompatible pear pollen tubes [76]. 


\subsection{ROS Are Involved in Signal Perception and Mediate Pollen Tube Rupture}

Signals that determine pollen tube growth direction include sporophyte-derived ROS, NO, polyamines, and peptides $[6,77,78]$; in many of these cases, ROS are also involved in signal perception [50].

In tobacco pollen tubes, polyamines applied at a low concentration $(10 \mu \mathrm{M})$ affected pollen elongation differentially [72]: putrescine negatively regulated pollen tube elongation; spermidine enhanced it, spermine had no effect on pollen tube growth. This influence of polyamines correlated well with their effect on ROS and/or NO levels in pollen tube tip: high NO and low ROS levels in the tip region of treated pollen tubes promoted while the opposite inhibited growth [72].

Recently, ROS was found to be involved in a signaling cascade triggered in response to a peptide signal (RALF4-RAPID ALKALINIZATION FACTOR 4), which is the pistil-side control of pollen tube growth. Exposure of tubes growing in vitro to this peptide caused a sharp increase in ROS level, growth stimulation and prevented tube rupture [79]. On the contrary, $\mathrm{H}_{2} \mathrm{O}_{2}$ quenchers potassium iodide and sodium pyruvate inhibited pollen tube growth and caused rupture. In plant lines that do not produce LORELEI-LIKE GPI-ANCHORED PROTEINS 2/3, involved in the perception of RALF signal, ROS level was significantly reduced, and growth was impaired. The addition of exogenous $\mathrm{H}_{2} \mathrm{O}_{2}$ partially restored these disturbances [79]. One of the proposed mechanisms was the regulation of the cell wall mechanical properties [7], since the deposition of callose and pectins in pollen tube wall of $l l g 2,3$ mutant was disrupted [79].

Pollen tube rupture upon reaching the embryo sac is a necessary condition for sperm release and, accordingly, for fertilization. This process is tightly controlled: recognition of the pollen tube by synergids and subsequent perception of "permitting" signal by the tube is required [8,80]. Signal peptides (for example, cysteine-rich peptides) and small molecules (for example, ROS), which allow synergid cells to recognize the pollen tube, are accumulated in the filiform apparatus (FA) area. FA is a highly thickened structure of synergids' cell wall at the micropylar end. Pollen tube recognition at this stage is an important barrier to interspecies crossing, since "unrecognized" pollen tube does not stop growth and does not release sperms [5]. Recognition involves receptor kinase FERONIA (FER), a member of the CrRLK1L (Catharanthus roseus receptor-like kinase 1-like) subfamily. It regulates NORTIA (NTA) membrane anchoring and interacts with the GPI-anchored protein LORELEI (LRI) on the synergid surface [7]. Lack of recognition and of the following rupture ("overgrowth phenotype") was found in Arabidopsis pistils with reduced ROS levels. In the FA area of the synergid, wild-type plants exhibit a ROS production peak, which is absent in fer and lre mutants, as well as in DPI-treated pistils. In all these cases tubes form the overgrowth phenotype and do not take part in fertilization [81]. Thus, receptor kinase FER, as well as the LRI interacting with it, are responsible for the local ROS production, which provokes tube rupture and sperm release. abstinence by mutual consent, amc, also has a phenotype similar to fer, but this mutant is self-sterile, that is, the phenotype is observed only when both male and female gamtophytes carry the amc allele. AMC encodes a peroxine involved in protein import in peroxisomes, potentially important for ROS production during pollen tube-synergid signaling [82].

\section{Conclusions}

Thus, ROS are involved in the life of the male gametophyte at all stages, from hydration to the release of sperms. On the one hand, ROS are produced endogenously, on the other, they act as a signal from female tissues. One of the main mechanisms of ROS action is the activation of ionic currents through the plasma membrane. Various ion transport systems exhibit sensitivity to ROS, but the specific pattern of their activity in each of the redox states, through which the male gametophyte passes, remains to be studied.

Author Contributions: Conceptualization, M.B.; writing—original draft preparation, E.K. and M.B.; writing—review and editing, M.B. Both authors have read and agreed to the published version of the manuscript.

Funding: This review was funded by the Russian Science Foundation (19-74-00036). 
Acknowledgments: We would like to thank ex-team members participated in the development of the topic of ROS and ion channels in our lab, Nikita Maksimov, Anna Smirnova, and Natalie Matveyeva.

Conflicts of Interest: The authors declare no conflict of interest.

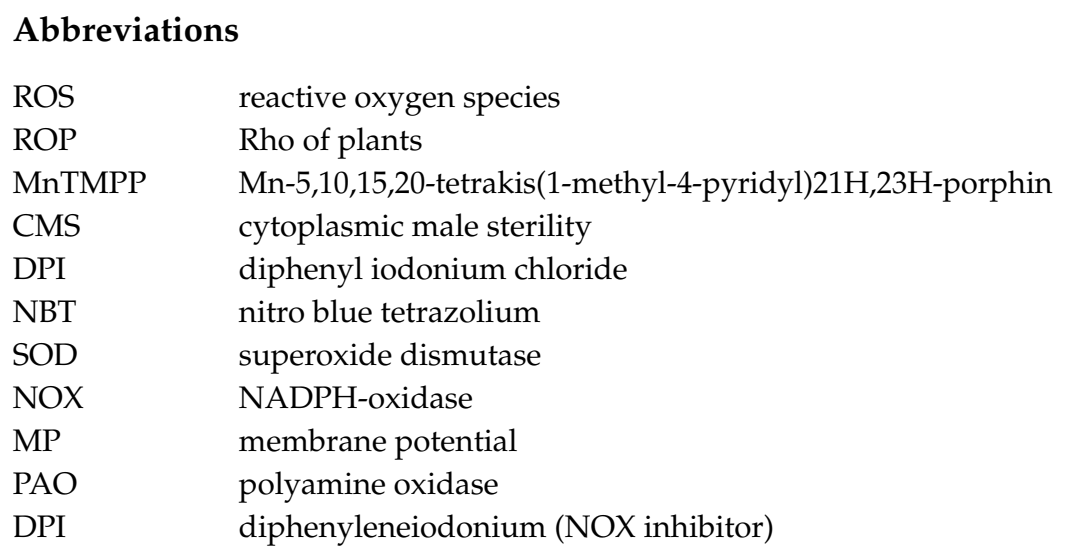

\section{References}

1. Bell, E.; Takeda, S.; Dolan, L. Reactive oxygen species in growth and development. In Reactive Oxygen Species in Plant Signaling. Signaling and Communication in Plants; Springer: Berlin/Heidelberg, Germany, 2009; pp. 43-53.

2. Kwak, J.M.; Mori, I.C.; Pei, Z.-M.; Leonhardt, N.; Torres, M.A.; Dangl, J.L.; Bloom, R.E.; Bodde, S.; Jones, J.D.G.; Schroeder, J.I. NADPH oxidase AtrbohD and AtrbohF genes function in ROS-dependent ABA signaling in Arabidopsis. EMBO J. 2003, 22, 2623-2633. [CrossRef] [PubMed]

3. Apel, K.; Hirt, H. REACTIVE OXYGEN SPECIES: Metabolism, Oxidative Stress, and Signal Transduction. Annu. Rev. Plant Biol. 2004, 55, 373-399. [CrossRef] [PubMed]

4. Coelho, S.M.B.; Brownlee, C.; Bothwell, J.H.F. A tip-high, $\mathrm{Ca}^{2+}$-interdependent, reactive oxygen species gradient is associated with polarized growth in Fucus serratus zygotes. Planta 2008, 227, 1037-1046. [CrossRef] [PubMed]

5. Johnson, M.A.; Harper, J.F.; Palanivelu, R. A Fruitful Journey: Pollen Tube Navigation from Germination to Fertilization. Annu. Rev. Plant Biol. 2019, 70, 809-837. [CrossRef]

6. Lopes, A.L.; Moreira, D.; Ferreira, M.J.; Pereira, A.M.; Coimbra, S. Insights into secrets along the pollen tube pathway in need to be discovered. J. Exp. Bot. 2019, 70, 2979-2992. [CrossRef]

7. Zhang, M.J.; Zhang, X.S.; Gao, X.-Q. ROS in the Male-Female Interactions During Pollination: Function and Regulation. Front. Plant Sci. 2020, 11, 1-8. [CrossRef]

8. Ge, Z.; Cheung, A.Y.; Qu, L.J. Pollen tube integrity regulation in flowering plants: Insights from molecular assemblies on the pollen tube surface. New Phytol. 2019, 222, 687-693. [CrossRef]

9. Weisenseel, M.H.; Jaffe, L.F. The major growth current through lily pollen tubes enters as K+ and leaves as H+. Planta 1976, 7, 1-7. [CrossRef]

10. DeFalco, T.A.; Bender, K.W.; Snedden, W.A. Breaking the code: $\mathrm{Ca}^{2+}$ sensors in plant signalling. Biochem. J. 2010, 425, 27-40. [CrossRef]

11. Feijó, J.A.; Wudick, M.M. Calcium is life. J. Exp. Bot. 2018, 69, 4147-4150. [CrossRef]

12. Taylor, L.P.; Hepler, P.K. Pollen germination and tube growth. Annu. Rev. Plant Physiol. Plant Mol. Biol. 1997, 48, 461-491. [CrossRef] [PubMed]

13. Speranza, A.; Crinelli, R.; Scoccianti, V.; Geitmann, A. Reactive oxygen species are involved in pollen tube initiation in kiwifruit. Plant Biol. 2012, 14, 64-76. [CrossRef] [PubMed]

14. Smirnova, A.V.; Matveyeva, N.P.; Polesskaya, O.G.; Yermakov, I.P. Generation of reactive oxygen species during pollen grain germination. Russ. J. Dev. Biol. 2009, 40, 345-353. [CrossRef]

15. Pasqualini, S.; Cresti, M.; Del Casino, C.; Faleri, C.; Frenguelli, G.; Tedeschini, E.; Ederli, L. Roles for NO and ROS signalling in pollen germination and pollen-tube elongation in Cupressus arizonica. Biol. Plant. 2015, 59, 735-744. [CrossRef] 
16. Huang, L.; Zhang, C.; Fang, M.; Xu, H.; Cao, M. The Cell Death in CMS Plants. Int. J. Biosci. Biochem. Bioinforma. 2011, 1, 297-301. [CrossRef]

17. Nie, H.; Cheng, C.; Hua, J. Mitochondrial proteomic analysis reveals that proteins relate to oxidoreductase activity play a central role in pollen fertility in cotton. J. Proteom. 2020, 225, 103861. [CrossRef]

18. Deng, M.-H.; Wen, J.-F.; Huo, J.-L.; Zhu, H.-S.; Dai, X.-Z.; Zhang, Z.-Q.; Zhou, H.; Zou, X.-X. Relationship of metabolism of reactive oxygen species with cytoplasmic male sterility in pepper (Capsicum annuum L.). Sci. Hortic. (Amsterdam) 2012, 134, 232-236. [CrossRef]

19. Li, S.; Wan, C.; Kong, J.; Zhang, Z.; Li, Y.; Zhu, Y. Programmed cell death during microgenesis in a Honglian CMS line of rice is correlated with oxidative stress in mitochondria. Funct. Plant Biol. 2004, 31, 369-376. [CrossRef]

20. Maksimov, N.; Evmenyeva, A.; Breygina, M.; Yermakov, I. The role of reactive oxygen species in pollen germination in Picea pungens (blue spruce). Plant Reprod. 2018, 18, 761-767. [CrossRef]

21. Kaya, H.; Nakajima, R.; Iwano, M.; Kanaoka, M.M.; Kimura, S.; Takeda, S.; Kawarazaki, T.; Senzaki, E.; Hamamura, Y.; Higashiyama, T.; et al. Ca2+-activated reactive oxygen species production by Arabidopsis RbohH and RbohJ is essential for proper pollen tube tip growth. Plant Cell 2014, 26, 1069-1080. [CrossRef]

22. Kaya, H.; Iwano, M.; Takeda, S.; Kanaoka, M.M.; Kimura, S. Apoplastic ROS production upon pollination by RbohH and RbohJ in Arabidopsis. Plant Signal. Behav. 2015. [CrossRef] [PubMed]

23. Smirnova, A.; Matveyeva, N.; Yermakov, I. Reactive oxygen species are involved in regulation of pollen wall cytomechanics. Plant Biol. 2013, 16, 252-257. [CrossRef] [PubMed]

24. Gao, X.Q.; Liu, C.Z.; Li, D.D.; Zhao, T.T.; Li, F.; Jia, X.N.; Zhao, X.Y.; Zhang, X.S. The Arabidopsis KIN $\beta \gamma$ Subunit of the SnRK1 Complex Regulates Pollen Hydration on the Stigma by Mediating the Level of Reactive Oxygen Species in Pollen. PLoS Genet. 2016, 12, 1-25. [CrossRef] [PubMed]

25. Breygina, M.A.; Matveeva, N.P.; Ermakov, I.P. The role of $\mathrm{Cl}^{-}$in pollen germination and tube growth. Russ. J. Dev. Biol. 2009, 40, 157-164. [CrossRef]

26. Breygina, M.; Smirnova, A.; Matveeva, N.; Yermakov, I. The role of anion channels in pollen germination and tube growth. In Pollen: Structure, Types and Effects; Kaiser, B.J., Ed.; Nova Science Publishers, Inc.: Hauppauge, NY, USA, 2010; pp. 1-19. ISBN 9781616686697.

27. Matveeva, N.P.; Andreyuk, D.S.; Voitsekh, O.O.; Ermakov, I.P. Regulatory Changes in the Intracellular pH and Cl- Efflux at Early Stages of Pollen Grain Germination in vitro. Russ. J. Plant Physiol. 2003, 50, 318-323. [CrossRef]

28. Rodriguez-Rosales, M.P.; Roldan, M.; Belver, A.; Donaire, J.P. Correlation between in vitro germination capacity and proton extrusion in olive pollen. Plant Physiol. Biochem. 1989, 27, 723-728.

29. Fricker, M.D.; White, N.S.; Obermeyer, G. pH gradients are not associated with tip growth in pollen tubes of Lilium longiflorum. J. Cell Sci. 1997, 110, 1729-1740.

30. Certal, A.C.; Almeida, R.B.; Carvalho, L.M.; Wong, E.; Moreno, N.; Michard, E.; Carneiro, J.; Rodriguéz-Léon, J.; $\mathrm{Wu}, \mathrm{H}$.; Cheung, A.Y.; et al. Exclusion of a proton ATPase from the apical membrane is associated with cell polarity and tip growth in Nicotiana tabacum pollen tubes. Plant Cell 2008, 20, 614-634. [CrossRef]

31. Mazina, S.E.; Matveyeva, N.P.; Yermakov, I.P. Determination of a functional pore in the pollen grain of tobacco. Tsitologiya 2002, 44, 33-39.

32. Weisenseel, M.H.; Nuccitelli, R.; Jaffe, L.F. Large electrical currents traverse growing pollen tubes. J. Cell Biol. 1975, 66, 556-567. [CrossRef]

33. Iwano, M.; Shiba, H.; Miwa, T.; Che, F.-S.; Takayama, S.; Nagai, T.; Miyawaki, A.; Isogai, A. Ca2+ dynamics in a pollen grain and papilla cell during pollination of Arabidopsis. Plant Physiol. 2004, 136, 3562-3571. [CrossRef] [PubMed]

34. Zafra, A.; Rejón, J.D.; Hiscock, S.J.; Alché, J.D.D. Patterns of ROS accumulation in the stigmas of angiosperms and visions into their multi-functionality in plant reproduction. Front. Plant Sci. 2016, 7, 1112-1119. [CrossRef] [PubMed]

35. McInnis, S.M.; Desikan, R.; Hancock, J.T.; Hiscock, S.J. Production of reactive oxygen species and reactive nitrogen species by angiosperm stigmas and pollen: Potential signalling crosstalk? New Phytol. 2006, 172, 221-228. [CrossRef] [PubMed]

36. Hiscock, S.J.; Bright, J.; McInnis, S.M.; Desikan, R.; Hancock, J.T. Signaling on the stigma. Potential new roles for ROS and NO in plant cell signaling. Plant Signal. Behav. 2007, 2, 23-24. [CrossRef] [PubMed] 
37. Bredemeijer, G.M.M. The role of peroxidases in pistil-pollen interactions. Theor. Appl. Genet. 1984, 68, $193-206$. [CrossRef] [PubMed]

38. Shivanna, K.R.; Rangaswamy, N.S. Pollen Biology: A Laboratory Manual; Springer Science \& Business Media: Berlin, Germany, 2012; ISBN 3642773060.

39. Žárský, V.; Říhová, L.; Tupý, J. Interference of pollen diffusable substances with peroxidase catalyzed reaction. Plant Sci. 1987, 52, 29-32. [CrossRef]

40. Kärkönen, A.; Kuchitsu, K. Reactive oxygen species in cell wall metabolism and development in plants. Phytochemistry 2015, 112, 22-32. [CrossRef]

41. Lindsay, S.E.; Fry, S.C. Redox and Wall-Restructuring. In The Expanding Cell; Verbelen, J.-P., Vissenberg, K., Eds.; Springer: Berlin/Heidelberg, Germany, 2007; pp. 159-190, ISBN 978-3-540-39116-6.

42. Bunzel, M. Chemistry and occurrence of hydroxycinnamate oligomers. Phytochem. Rev. 2010, 9, 47-64. [CrossRef]

43. Breygina, M.; Maksimov, N.; Polevova, S.; Evmenyeva, A. Bipolar pollen germination in blue spruce (Picea pungens). Protoplasma 2019, 256, 941-949. [CrossRef]

44. Çetinbaş-Genç, A.; Vardar, F. Effect of methyl jasmonate on in-vitro pollen germination and tube elongation of Pinus nigra. Protoplasma 2020, 257, 1655-1665. [CrossRef]

45. Breygina, M.A.; Abramochkin, D.V.; Maksimov, N.M.; Yermakov, I.P. Hydrogen peroxide affects ion channels in lily pollen grain protoplasts. Plant Biol. 2016, 18,761-767. [CrossRef] [PubMed]

46. Wu, J.; Shang, Z.; Wu, J.; Jiang, X.; Moschou, P.N.; Sun, W.; Roubelakis-Angelakis, K.A.; Zhang, S. Spermidine oxidase-derived $\mathrm{H} 2 \mathrm{O} 2$ regulates pollen plasma membrane hyperpolarization-activated Ca2+-permeable channels and pollen tube growth. Plant J. 2010, 63, 1042-1053. [CrossRef] [PubMed]

47. Maksimov, N.M.; Breygina, M.A.; Ermakov, I.P. Regulation of ion transport across the pollen tube plasmalemma by hydrogen peroxide. Cell Tissue Biol. 2016, 10, 69-75. [CrossRef]

48. Hafidh, S.; Fila, J.; Honys, D. Male gametophyte development and function in angiosperms: A general concept. Plant Reprod. 2016, 29, 31-51. [CrossRef]

49. Scholz, P.; Anstatt, J.; Krawczyk, H.E.; Ischebeck, T. Signalling Pinpointed to the Tip: The Complex Regulatory Network That Allows Pollen Tube Growth. Plants 2020, 9, 1098. [CrossRef]

50. Sankaranarayanan, S.; Ju, Y.; Kessler, S.A. Reactive Oxygen Species as Mediators of Gametophyte Development and Double Fertilization in Flowering Plants. Front. Plant Sci. 2020, 11, 1199. [CrossRef]

51. Lan, X.; Yang, J.; Abhinandan, K.; Nie, Y.; Li, X.; Li, Y.; Samuel, M.A. Flavonoids and ROS Play Opposing Roles in Mediating Pollination in Ornamental Kale (Brassica oleracea var. acephala). Mol. Plant 2017, 10, 1361-1364. [CrossRef]

52. Iwano, M.; Entani, T.; Shiba, H.; Kakita, M.; Nagai, T.; Mizuno, H.; Miyawaki, A.; Shoji, T.; Kubo, K.; Isogai, A.; et al. Fine-tuning of the cytoplasmic Ca2+ concentration is essential for pollen tube growth. Plant Physiol. 2009, 150, 1322-1334. [CrossRef]

53. Gutermuth, T.; Lassig, R.; Portes, M.; Maierhofer, T.; Romeis, T.; Borst, J.; Hedrich, R.; Feijó, J.A.; Konrad, K.R. Pollen tube growth regulation by free anions depends on the interaction between the anion channel SLAH3 and calcium-dependent protein kinases CPK2 and CPK20. Plant Cell 2013, 25, 4525-4543. [CrossRef]

54. Breygina, M.; Smirnova, A.; Matveeva, N.; Yermakov, I. Membrane potential changes during pollen germination and tube growth. Cell Tissue Biol. 2010, 3, 573-582. [CrossRef]

55. Podolyan, A.; Maksimov, N.; Breygina, M. Redox-regulation of ion homeostasis in growing lily pollen tubes. J. Plant Physiol. 2019, 243, 153050. [CrossRef]

56. Hepler, P.K.; Winship, L.J. The pollen tube clear zone: Clues to the mechanism of polarized growth. J. Integr. Plant Biol. 2015, 57, 79-92. [CrossRef] [PubMed]

57. Feijó, J.A.; Sainhas, J.; Hackett, G.R.; Kunkel, J.G.; Hepler, P.K. Growing pollen tubes possess a constitutive alkaline band in the clear zone and a growth-dependent acidic tip. J. Cell Biol. 1999, 144, 483-496. [CrossRef] [PubMed]

58. Michard, E.; Lima, P.T.; Borges, F.; Silva, A.C.; Portes, M.T.; Carvalho, J.E.; Gilliham, M.; Liu, L.-H.; Obermeyer, G.; Feijó, J. a Glutamate receptor-like genes form Ca2+ channels in pollen tubes and are regulated by pistil D-serine. Science 2011, 332, 434-437. [CrossRef] [PubMed]

59. Fernando, D.D.; Lazzaro, M.D.; Owens, J.N. Growth and development of conifer pollen tubes. Sex. Plant Reprod. 2005, 18, 149-162. [CrossRef] 
60. Cai, G.; Parrotta, L.; Cresti, M. Organelle trafficking, the cytoskeleton, and pollen tube growth. J. Integr. Plant Biol. 2015, 57, 63-78. [CrossRef]

61. Qian, D.; Xiang, Y. Actin cytoskeleton as actor in upstream and downstream of calcium signaling in plant cells. Int. J. Mol. Sci. 2019, 20, 1403. [CrossRef]

62. Lovy-Wheeler, A.; Kunkel, J.G.; Allwood, E.G.; Hussey, P.J.; Hepler, P.K. Oscillatory increases in alkalinity anticipate growth and may regulate actin dynamics in pollen tubes of lily. Plant Cell 2006, 18, 2182-2193. [CrossRef]

63. Chen, C.Y.; Wong, E.I.; Vidali, L.; Estavillo, A.; Hepler, P.K.; Wu, H.M.; Cheung, A.Y. The regulation of actin organization by actin-depolymerizing factor in elongating pollen tubes. Plant Cell 2002, 14, 2175-2190. [CrossRef]

64. Muhlemann, J.K.; Younts, T.L.B.; Muday, G.K. Flavonols control pollen tube growth and integrity by regulating ROS homeostasis during high-temperature stress. Proc. Natl. Acad. Sci. USA 2018, 115, E11188-E11197. [CrossRef]

65. Do, T.H.T.; Choi, H.; Palmgren, M.; Martinoia, E.; Hwang, J.U.; Lee, Y. Arabidopsis ABCG28 is required for the apical accumulation of reactive oxygen species in growing pollen tubes. Proc. Natl. Acad. Sci. USA 2019, 116, 12540-12549. [CrossRef]

66. Aloisi, I.; Cai, G.; Tumiatti, V.; Minarini, A.; Del Duca, S. Del Natural polyamines and synthetic analogues modify the growth and the morphology of Pyrus communis pollen tubes affecting ROS levels and causing cell death. Plant Sci. 2015, 239, 92-105. [CrossRef] [PubMed]

67. Liu, P.; Li, R.L.; Zhang, L.; Wang, Q.L.; Niehaus, K.; Baluška, F.; Šamaj, J.; Lin, J.X. Lipid microdomain polarization is required for NADPH oxidase-dependent ROS signaling in Picea meyeri pollen tube tip growth. Plant J. 2009, 60, 303-313. [CrossRef] [PubMed]

68. Potocký, M.; Jones, M.A.; Bezvoda, R.; Smirnoff, N.; Žárský, V. Reactive oxygen species produced by NADPH oxidase are involved in pollen tube growth. New Phytol. 2007, 174, 742-751. [CrossRef] [PubMed]

69. Lassig, R.; Gutermuth, T.; Bey, T.D.; Konrad, K.R.; Romeis, T. Pollen tube NAD(P)H oxidases act as a speed control to dampen growth rate oscillations during polarized cell growth. Plant J. 2014, 78, 94-106. [CrossRef]

70. Aloisi, I.; Cai, G.; Serafini-Fracassini, D.; Del Duca, S. Polyamines in Pollen: From Microsporogenesis to Fertilization. Front. Plant Sci. 2016, 7, 155. [CrossRef]

71. Liu, T.; Kim, D.W.; Niitsu, M.; Maeda, S.; Watanabe, M.; Kamio, Y.; Berberich, T.; Kusano, T. Polyamine Oxidase 7 is a Terminal Catabolism-Type Enzyme in Oryza sativa and is Specifically Expressed in Anthers. Plant Cell Physiol. 2014, 55, 1110-1122. [CrossRef]

72. Benkő, P.; Jee, S.; Kaszler, N.; Fehér, A.; Gémes, K. Polyamines treatment during pollen germination and pollen tube elongation in tobacco modulate reactive oxygen species and nitric oxide homeostasis. J. Plant Physiol. 2020, 244, 153085. [CrossRef]

73. Pottosin, I.; Shabala, S. Polyamines control of cation transport across plant membranes: Implications for ion homeostasis and abiotic stress signaling. Front. Plant Sci. 2014, 5, 154. [CrossRef]

74. Aloisi, I.; Cai, G.; Faleri, C.; Navazio, L.; Serafini-Fracassini, D.; Del Duca, S. Spermine Regulates Pollen Tube Growth by Modulating Ca2+-Dependent Actin Organization and Cell Wall Structure. Front. Plant Sci. 2017, 8, 1701. [CrossRef]

75. Cárdenas, L.; McKenna, S.T.; Kunkel, J.G.; Hepler, P.K. NAD(P)H oscillates in pollen tubes and is correlated with tip growth. Plant Physiol. 2006, 142, 1460-1468. [CrossRef]

76. Wang, C.L.; Wu, J.; Xu, G.H.; Gao, Y.B.; Chen, G.; Wu, J.Y.; Wu, H.Q.; Zhang, S.L. S-RNase disrupts tip-localized reactive oxygen species and induces nuclear DNA degradation in incompatible pollen tubes of Pyrus pyrifolia. J. Cell Sci. 2010, 123, 4301-4309. [CrossRef]

77. Pereira, A.M.; Lopes, A.L.; Coimbra, S. Arabinogalactan proteins as interactors along the crosstalk between the pollen tube and the female tissues. Front. Plant Sci. 2016, 7, 1-15. [CrossRef] [PubMed]

78. Mizuta, Y.; Higashiyama, T. Chemical signaling for pollen tube guidance at a glance. J. Cell Sci. $2018,131$. [CrossRef] [PubMed]

79. Feng, H.; Liu, C.; Fu, R.; Zhang, M.; Li, H.; Shen, L.; Wei, Q.; Sun, X.; Xu, L.; Ni, B.; et al. LORELEI-LIKE GPI-ANCHORED PROTEINS 2/3 Regulate Pollen Tube Growth as Chaperones and Coreceptors for ANXUR/BUPS Receptor Kinases in Arabidopsis. Mol. Plant 2019, 12, 1612-1623. [CrossRef]

80. Li, H.J.; Yang, W.C. Ligands Switch Model for Pollen-Tube Integrity and Burst. Trends Plant Sci. 2018, 23, 369-372. [CrossRef] [PubMed] 
81. Duan, Q.; Kita, D.; Johnson, E.A.; Aggarwal, M.; Gates, L.; Wu, H.-M.; Cheung, A.Y. Reactive oxygen species mediate pollen tube rupture to release sperm for fertilization in Arabidopsis. Nat. Commun. 2014, 5, 3129. [CrossRef]

82. Boisson-Dernier, A.; Frietsch, S.; Kim, T.-H.; Dizon, M.B.; Schroeder, J.I. The peroxin loss-of-function mutation abstinence by mutual consent disrupts male-female gametophyte recognition. Curr. Biol. 2008, 18, 63-68. [CrossRef]

Publisher's Note: MDPI stays neutral with regard to jurisdictional claims in published maps and institutional affiliations.

(C) 2020 by the authors. Licensee MDPI, Basel, Switzerland. This article is an open access article distributed under the terms and conditions of the Creative Commons Attribution (CC BY) license (http://creativecommons.org/licenses/by/4.0/). 